Weed Plates Series 3, Plates 6I-90

By Prof. Dr. E. Korsmo. $84 \mathrm{~cm} . \times 64 \mathrm{~cm}$. With Textbook of 140 pp. (Leipzig : Koehler and Volckmar A. G. and Co.) 22 gold marks.

$7 \mathrm{HE}$ third set of Prof. Korsmo's weed plates completes a series of ninety plates which are unequalled by any previous publication anywhere. in the world. They are bold, colourful and easily understood by the most elementary student, but only a trained botanist can appreciate the accuracy of delineation and the skill with which the salient points have been selected. The illustrations of each weed provide an epitome of the life-history from seed to seed. Germination, seedling stages, mature plants, methods of propagation and seed dispersal all find their place.

Unusual details which frequently escape observation often throw light on the ecological behaviour of various species. In Cardamine pratensis, for example, rooting from the base of the leaflets of the lower leaves provides for now plantlets and continuous propagation. In Cuscuta the process of attachment of the young seedling to the host, and the withdrawal of the dodder from the soil explains the apparent mystery of how such a total parasite spreads by means of seeds. Examples might be multiplied to show the great value of these charts for teaching purposes. Their usefulness is enhanced by the booklet of explanatory notes published in various languages, with direct reference to the drawings.

Prof. Korsmo is to be congratulated on a valuable piece of work brought to a successful conclusion with the co-operation of an able staff of draughtsmen, who achieved the difficult task of combining scientific accuracy with true pictorial representation of the living plant.

Reports of the Progress of Applied Chemistry Issued by the Society of Chemical Industry. Vol. 23, 1938. Pp. 861. (London : Society of Chemical Industry, 1939.) 7s. 6d.; to non-members, 12s. $6 d$.

T $\mathrm{T}$ is, perhaps, scarcely necessary to remark that, 1 although these excellent annual reports are written by chemists and chemical engineers, they find many readers beyond the confines of the profession. While much of the information which they contain is admittedly of purely chemical interest and value, one cannot easily divorce chemistry from physics, engineering, or biology, and there is much which cannot fail to interest medical men, economists, and indeed all who have a lively concern in the more important phases of scientific industry. Any one volume is much the same in form as its predecessor, but considerable variations in substance in fact arise from such changes in authorship as occur from time to time.

In the report for 1938 there are twenty-seven chapters, including a report on explosives covering the period 1937-1938, and one on plastics. Of these, comparison with the previous report shows that in seven cases there has been a complete change of author, whilst in several others the responsibility has been differently shared among joint authors. In the present volume, plant and machinery are discussed by S. G. M. Ure and F. J. Bailey; pulp and paper by T. T. Potts; iron and steel by S. J. Kennett; soils and fertilizers by G. V. Jacks; sugar by H. C. S. de Whalley; fine chemicals, medicinal substances, and essential oils by T. M. Sharp and W. Solomon; photographic materials and processes by C. Waller; and explosives by J. Weir.

A. A. E.

\section{The Annual Register}

A Review of Public Events at Home and Abroad for the Year 1938. Edited by Dr. M. Epstein. Pp. xii +498 . (London, New York and Toronto : Longmans, Green and Co., Ltd., 1939.) 30s. net.

A GAIN this volume gives a survey of the year's $A$ history. In spite of a troubled year, crowded with events of great significance, the volume maintains its usual compass and departs in no respect from the customary allocation of space. Home, Imperial and foreign history again occupy rather more than half the volume, and much skill has evidently been exercised in the narrative of European events. No fault can be found with the factual record ; every event of significance is mentioned, and in the main the survey is objective, though here and there a party point of view is manifest. The second part begins with a chronicle of events and is followed by a retrospect of literature, art and science in 1938 . The section on science, though short, is a most comprehensive survey of work and publications of the year. Finally, there are the usual résumés of finance, commerce and law and obituaries of eminent persans. The public documents printed in full are of unusual interest since they include the AngloItalian Agreement of April 1938 and the famous Munich Agreement of September last.

\section{Observation and Protocol Statement}

By Dr. Bent Schultzer. Pp. ix +151. (Copenhagen : Levin and Munksgaard; London: Williams and Norgate, Ltd., 1938.) 7s. $6 d$. net.

DHILOSOPHICAL discussions about our knowledge of the external world have drifted more and more towards linguistic considerations. This is mainly the case with logical positivism, which asserts the importance of the logic and language of science at the expense of metaphysics. In this line of thought, Dr. Schultzer asks himself the question, How can an observation be validly registered in language ? A close analysis of the condition of observation and of the content and structure of the so-called "protocol statements" (elementary propositions about direct observations) shows him that the only possible way of answering it correctly is by stating explicitly the presuppositions of a valid linguistic formulation of observations tacitly recognized by every empirical observer. It is the discussion of these presuppositions which forms the object of this book. Even if the results obtained are not final, Dr. Schultzer's treatment of the problem, especially when he proposes alternatives to the narrow orthodoxy of the Vienna circle, is both refreshing and useful. T. G. 